Journal of Vaccines \& Immunization

\title{
Suboptimal vaccination rates in rural Ghana despite positive caregiver attitudes towards vaccination
}

Daniel Ansong ${ }^{1}$, Daniel Tawfik², Emmanuel Ato Williams ${ }^{1,3, *}$, Scott Benson², Isaac Nyanor ${ }^{1}$, Isaac Boakye ${ }^{1}$, Christian Obirikorang ${ }^{3}$, Lorraine Sallah', Bernard Arhin ${ }^{1}$, Joseph Marfo Boaheng ${ }^{1}$, Evans Amuzu ${ }^{1}$, Osei Asibey ${ }^{1}$ and Ty Dickerson ${ }^{2}$

\footnotetext{
${ }^{1}$ Komfo Anokye Teaching Hospital, Kumasi, Ghana

${ }^{2}$ Department of Pediatrics, University of Utah, Utah, USA

${ }^{3}$ University of Surrey Clinical Research Centre, Egerton Road, Guildford, GU2 7XP, UK

${ }^{4}$ Kwame Nkrumah University of Science and Technology, Kumasi, Ghana
}

\begin{abstract}
Background: Vaccines save more than 3 million lives and prevent 750,000 disabilities each year. Optimum immunization coverage will help in the fight against infectious diseases. This study was carried out to characterize current knowledge, attitudes, and practices regarding immunizations in a rural Ghanaian community and to help identify reasons for delayed vaccination and suboptimal vaccination rates. Methods: A cross-sectional study was conducted in July 2013 on 156 parents and caregivers of children aged between 1 month and 5 years old. Structured questionnaires were administered to elicit responses on knowledge, attitudes, and practices towards childhood immunization. Results: Almost all study participants knew about vaccination (98.7\%). However, unsolicited awareness of the benefits of vaccination was poor, and there existed knowledge gaps about vaccine preventable diseases. Nonetheless, most study participants (94.8\%) acknowledged every child's right to vaccination. The most prominent factors that influence the decision to participate in vaccination include recommendation by a local nurse (13.2\%) or other health worker (10.4\%), or a supportive spouse $(11.8 \%)$. Adherence to vaccination schedules were generally low, but parents with a primary educational level were approximately 6 times more likely to adhere to vaccination schedules for the routine expanded programme on immunization vaccines than were parents with a secondary level of education. Conclusion: There was an almost universal awareness of vaccination among study participants. But poor knowledge of the benefits of vaccination and of vaccine preventable diseases ought to be addressed through education in order to promote improved and timely vaccination coverage.
\end{abstract}

Keywords: suboptimal vaccination; vaccine preventable diseases; Knowledge; Attitudes; Ghana

\section{Introduction}

Childhood vaccination has been one of the most successful public health interventions worldwide, preventing more than 3 million deaths and 750,000 disabilities each year [1]. One of the estimates of the decade of vaccines [20112020] is that between 24.6 and 25.8 million deaths could potentially be averted via maintenance and enhancement of current immunization efforts compared to no vaccination by 2020 [2]. These vaccines protect against many infectious diseases which account for a great deal of morbidity and mortality in low and middle-income countries [3], including $64 \%$ of under-five child mortality (U5M) [4]. Currently available vaccines can protect against about 30 diseases, and the quest to develop other vaccines continues.

Vaccination is the administration of a vaccine to stimulate an individual's immune system in order to develop specific immunity to a disease causing organism; and immunization is the process by which an individual's immune system becomes fortified against an agent of disease [5]. Immunization can be achieved in an active

*Corresponding author: Dr. Emmanuel Ato Williams, University of Surrey Clinical Research Centre, Egerton Road, Guildford, GU2 7XP, UK. Tel.: +44 7593816114; Fax: +44 1483689790; Email: williams_ato@ yahoo.com

Received 18 June 2014 Revised 2 August 2014 Accepted 12 August 2014 Published 19 August 2014

Citation: Ansong D, Tawfik D, Williams EA, Benson S, Nyanor I, Boakye I, Obirikorang C, Sallah L, Arhin B, Boaheng JM, Amuzu E, Asibey O, Dickerson T (2014) Suboptimal vaccination rates in rural Ghana despite positive caregiver attitudes towards vaccination. J Vaccines Immun 2:715. doi:10.14312/2053-1273.2014-2

Copyright: (C) 2014 Ansong D, et al. This is an open-access article distributed under the terms of the Creative Commons Attribution License, which permits unrestricted use, distribution and reproduction in any medium, provided the original author and source are credited. 
or passive manner: vaccination is an active form of immunization, and the two terms are used interchangeably in this study.

Immunization is a proven and cost effective tool for control of infectious diseases [6, 7]. Vaccine preventable infections includes diphtheria, Haemophilus influenzae type $B$, hepatitis $A$, hepatitis $B$, human papilloma virus, influenza, measles, meningococcus, mumps, pertussis, pneumococcus, polio, rotavirus, rubella, smallpox, and tetanus. However, with the exception of smallpox, which was declared globally eradicated in 1980, preventable morbidity from these infections persists [8]. Immunization is essential to the attainment of the Millennium Development Goal (MDG) 4 and reducing childhood mortality by two-thirds during period of 1990 and 2015. The average annual rate of reduction [AARR] in U5M rate observed from 1990 to 2006 was 1\% in SubSaharan Africa (SSA); but an AARR of $10.5 \%$ between 2007 and 2015 is required for the region to succeed at not missing the MDG 4 target [9]. Worldwide, the mortality rate for children under five dropped by 47 per cent from 90 deaths per 1,000 live births in 1990 to 48 in 2012 [10]. Although in SSA there was a similar $45 \%$ drop in the U5M within the stated period, the region still accounts for the significant majority of the global mortality - with one in ten children dying before age five (more than 15 times the average for developed regions) [10]. The prospect of achieving the MDG 4 is under threat if vaccination rates remain suboptimal [11]. Thus, maintaining and enhancing current immunization coverage and quality is necessary and requires improvements in both the supply and demand for immunization [12]. It is essential to understand caregivers' knowledge, attitudes and practices regarding childhood immunization as these factors impact demand for immunization.

A study on the knowledge, attitudes and practices of immunization in an urban educated population of India [13] identified considerable variation in vaccine awareness from one vaccine to another. In addition, prior work in Kumasi, Ghana, in 1999 by Browne et al. [14] found that full immunization coverage of the children of mothers who had been educated beyond primary level was higher than that of the other children (75.9\% v. 65.2\%). Elsewhere, studies have indicated that understanding the parental perceptions and knowledge about immunizations would help health policy makers to develop better health education programmes [15-19].

Psychosocial behaviours using the Health Belief Model (HBM) have established that a person's health related behavior is directly related to the perceived levels of threat. The HBM, first developed in the 1950s by social psychologists Hochbaum, Rosenstock and Kegels, has since then been adapted to explore a variety of long and short term health behaviours, including sexual risk behaviors and the transmission of the human immunodeficiency virus (HIV). Its main assumptions include the following: A person will take a health related action (eg. condom use) if he/she: i) Feels that a negative health condition (ie. HIV) can be avoided, ii) Has a positive expectation that by taking a recommended action, he/she will avoid a negative health condition (ie. using condoms will be effective at preventing HIV), and iii) Believes that he/she can successfully take a recommended health action (ie. can use condoms comfortably and with confidence).

The HBM has been applied to a broad range of health behaviours and subject populations including the following: i) Preventive health behaviors, which include health promoting (eg. diet, exercise) and health risk (eg. smoking) behaviours as well as vaccination and contraceptive practices, ii) Sick role behaviors, which refer to compliance with recommended medical regimens, usually following professional diagnosis of illness and iii) Clinic use, which includes physician visits for a variety of reasons [20].

Various studies have identified that adherence to vaccine schedules tend to be highest at birth for hospital deliveries, but subsequently fall due to various factors, including low levels of knowledge of vaccine specific schedules and gaps between awareness and adherence to vaccine schedules [21-23]. Due to suboptimal vaccination rates, we aimed to evaluate current knowledge, attitudes, and practices of parents and caregivers of children between 1 month and 5 years old in the Barekese subdistrict of Ghana regarding immunizations; through a mixed quantitative-qualitative survey as part of the Barekuma Community Collaborative Development Programme (BCCDP) [24].

\section{Materials and methods}

\section{Study area and setting}

The BCCDP is a collaborative partnership between 20 rural Ghanaian communities near Kumasi and researchers from the Komfo Anokye Teaching Hospital in Kumasi, Ghana, the Kwame Nkrumah University of Science and Technology in Kumasi, Ghana, and the University of Utah School of Medicine in Salt Lake City, Utah, USA. The collaboration focuses on community development efforts primarily involving medical care, health education, and economic development. The BCCDP study area is found in the Barekese subdistrict, one of the eight sub-districts of the Atwima Nwabiagya District in the Ashanti Region of Ghana. The Barekese subdistrict has a population of approximately 18,510, with a female-to-male ratio of 1.1:1. The Barekuma community is a traditional, mostly, Ashanti community with other Ghanaian tribes in the minority. Their typical socioeconomic activities include farming and trading. The study setting is a typical African setting that believes in both traditional and orthodox medicine that may be swayed depending on the strength of evidence demonstrated to the particular health intervention.

\section{Study design, sample size, sampling and recruitment of participants}

A random cross-sectional sampling of study participants was made. Study investigators assigned numbers based 
on previous census conducted in the community and randomly selected households that were visited in the community. A cross section of parents and caregivers with children aged 1 month to 5 years were deemed as eligible for inclusion.

\section{Sample size calculation}

According to the Ghana Demographic and Health Survey [25], seventy nine percent of Ghanaian children aged 12 to 23 months old are fully immunised. Assuming a reliability coefficient of 1.96 which corresponds to a confidence level of 95 percent and a precision error of 7 percent, a minimum sample size of 156 was estimated. A non-response of 20 percent was accounted for.

Using the formula, $n=z^{2} p q / d^{2}$ [26], where $n=$ the desired sample size and $\mathrm{z}=$ reliability coefficient of 1.96 which corresponds to 95 per cent confidence interval (CI), $\mathrm{p}=$ proportion of children aged 12-23 months who were believed to be vaccinated in Ghana in 2008.

$\mathrm{q}=1-\mathrm{p} ; \mathrm{p}=79 \%=0.79$ and so $\mathrm{q}=1-0.79=0.21$

$\mathrm{d}=$ precision error; $\mathrm{d}=7 \%=0.07$

$\mathrm{z}=1.96(95 \%$ C.I $)$

$\mathrm{n}=(1.96)^{2}(0.79)(1-0.79) /(0.07)^{2} ; \mathrm{n}=130$

Taking into account a non-response rate of 20 percent, the minimum required sample size was determined to be 156.

Individuals were recruited via a door-to-door approach. Selected households which did not have parents or caregivers considered eligible for inclusion in the study (ie. with no child aged 1 month to 5 years old) were replaced with other households with eligible participants. Written informed consent was obtained at study entry. Individuals were at liberty to abstain from any component of the interview or the entire study. No eligible participants who were contacted declined to participate, but not all completed all questions (see below).

This study employed face-to-face administered structured questionnaire with both open-ended and close-ended questions. The questionnaire obtained information on sociodemographic information as well as various questions assessing knowledge, attitudes, and practices of participants on childhood vaccination. Participants were asked questions on items such as source of knowledge on vaccination, benefits of childhood vaccination, and factors that encourage or discourage visits to child immunization centers.

We also extracted information on vaccine schedules from the available child health records as part of information for the data analysis.

\section{Interviews}

The questionnaires were administered in either the local (Twi) or English language, depending on the preference of the study participant, but data entry and subsequent analysis were all in English. Four teams of health professionals had undergone a 2-day orientation on the study protocols and translation of English to Twi to help streamline translation of the questionnaire.

Scheduled vaccination was defined by this study as the administration of the vaccine according to Ghana's Expanded Programme on Immunization (EPI) recommended schedule or within 1 week before or after this recommendation. Whereas unscheduled vaccination was defined as the administration of the vaccine in any time period beyond 1 week of the recommended schedule for a particular vaccine. Where there was no available documentation of vaccine administration, this was referred to as 'not recorded' (Table 4).

\section{Data analysis}

Data were coded and entered on a daily basis into EpiInfo (TM) 3.5.1 software (Centers for Disease Control and Prevention, 1600 Clifton Rd., Atlanta, GA, USA). The data were analyzed using STATA/SE 11.1 (StataCorp, 4905 Lakeway Drive, College Station, TX, USA). Basic summaries of participants' sociodemographic characteristics and responses to the questionnaire were provided along with percentages. The vaccination scheduled/ unscheduled rates of the child of any given participant were determined based on available information in the Child Health Record (Vaccination Card) at the time of an interview. Logistic regression model of vaccines and demographic characteristics were explored. A binary outcome of a response variable (vaccine either scheduled or unscheduled) and predictor variables (demographic characteristics) were developed for the regression.

\section{Ethical approval}

The study protocol was approved by the Committee on Human Research Publication and Ethics of the Kwame Nkrumah University of Science and Technology, School of Medical Sciences/Komfo Anokye Teaching Hospital (KNUST-SMS/KATH), Kumasi.

\section{Results}

\section{Baseline characteristics}

This study interviewed 156 individuals, consisting of 145 mothers, 5 fathers, and 6 caregivers of children between 1 month and 5 years old in the Barekese subdistrict. One hundred and forty three participants (143) completed all sections of the interview, giving a completion rate of $92 \%$.

The median age of the study participants was 27 years (Table 1). Majority of the respondents were female (96.8\%). Most of the study participants were either married $(35.3 \%)$ or cohabiting with a spouse $(42.3 \%)$, but single parents or caretakers constituted almost $18 \%$. The median number of children per respondent was 3 (Inter-quartile range [IQR] 1-4) and the median age of the youngest child was 18 months (IQR: 8.5-34 months). The highest level of education completed by most 
(55.1\%) of the participants was up to the primary level; whereas $26.3 \%$ had no education at all. The majority of the participants were either traders $(30.8 \%)$ or farmers $(30.1 \%)$ and $17.3 \%$ were unemployed.

Table 1 Baseline demographic characteristics of parents and caregivers.

\begin{tabular}{|c|c|c|}
\hline Characteristics ( $n=156$ ) & $N(\%)$ & Median (IQR) \\
\hline Age of Respondents & & $27(23-33)$ years \\
\hline \multicolumn{3}{|l|}{ Sex } \\
\hline Male & $5(3.21)$ & \\
\hline Female & 151(96.79) & \\
\hline
\end{tabular}

Marital Status

$\begin{array}{ll}\text { Single } & \text { 28(17.95) } \\ \text { Married } & 55(35.26) \\ \text { Co-habiting } & 66(42.31) \\ \text { Separated } & 4(2.56) \\ \text { Widow } & 3(1.92)\end{array}$

How are you related to this child?

$\begin{array}{ll}\text { Mother } & 145(92.95) \\ \text { Father } & 5(3.21) \\ \text { Other } & 6(3.85)\end{array}$

Number of Children

Age of last born (months)

$3(1-4)$

Highest level of Education

$\begin{array}{ll}\text { None } & 41(26.28) \\ \text { Primary } & 86(55.13) \\ \text { Secondary } & 16(10.26) \\ \text { Other } & 13(8.33)\end{array}$

Profession

$\begin{array}{ll}\text { Unemployment } & 27(17.31) \\ \text { Farmer } & 47(30.13) \\ \text { Artisan } & 22(14.1) \\ \text { Trader } & 48(30.77) \\ \text { Other } & 12(7.69)\end{array}$

\section{Knowledge about childhood vaccination}

Almost all the parents and caregivers interviewed in this study (98.7\%) had heard about childhood vaccination, (Table 2). The most commonly cited sources of this knowledge included hospitals (58.3\%), clinics (12.8\%), community announcements (39.7\%), radio (28.8\%), and television $(12.8 \%)$.
Table 2 Parents and caregivers knowledge on vaccination.

\begin{tabular}{|c|c|c|c|}
\hline \multirow[b]{2}{*}{ Vaccination } & \multicolumn{3}{|c|}{ Response $=n(\%)$} \\
\hline & Mentioned & $\begin{array}{l}\text { Not } \\
\text { mentioned }\end{array}$ & $\begin{array}{l}\text { Don't } \\
\text { know }\end{array}$ \\
\hline $\begin{array}{l}\text { Heard about childhood } \\
\text { vaccination }\end{array}$ & $154(98.72)$ & $2(1.28)$ & \\
\hline \multicolumn{4}{|c|}{ Place heard of childhood vaccination } \\
\hline Hospital & $91(58.33)$ & $65(41.67)$ & \\
\hline $\begin{array}{l}\text { Community } \\
\text { announcement }\end{array}$ & $62(39.74)$ & $94(60.26)$ & \\
\hline Clinic & $20(12.82)$ & $136(87.18)$ & \\
\hline TV & $20(12.82)$ & $136(87.18)$ & \\
\hline Church & $4(2.56)$ & $152(97.44)$ & \\
\hline Mosque & $3(1.92)$ & $153(98.08)$ & \\
\hline \multicolumn{4}{|c|}{ Benefits of vaccination to child } \\
\hline $\begin{array}{l}\text { To prevent a } \\
\text { potential spread of } \\
\text { disease }\end{array}$ & $75(48.08)$ & $81(51.92)$ & \\
\hline Prevent measles & $64(41.03)$ & $92(58.97)$ & \\
\hline Prevent polio & $61(39.10)$ & $95(60.90)$ & \\
\hline Prevent tetanus & $29(18.59)$ & $127(81.41)$ & \\
\hline Prevent convulsion & $14(8.97)$ & $142(91.03)$ & \\
\hline $\begin{array}{l}\text { Prevent } \\
\text { malnutrition }\end{array}$ & $11(7.05)$ & $145(92.95)$ & \\
\hline Prevent tuberculosis & $11(7.05)$ & $145(92.95)$ & \\
\hline Prevent diarrhoea & $8(5.13)$ & $148(94.87)$ & \\
\hline $\begin{array}{l}\text { To increase the } \\
\text { weight of the child }\end{array}$ & $4(2.56)$ & $152(97.44)$ & \\
\hline Prevent rotavirus & $2(1.28)$ & $154(98.72)$ & \\
\hline Prevent pneumonia & $1(0.64)$ & 155(99.36) & \\
\hline Prevent asthma & $1(0.64)$ & $155(99.36)$ & \\
\hline
\end{tabular}

Childhood disease prevention by vaccination

\begin{tabular}{lrrr} 
Tetanus toxoid & $119(77.27)$ & $5(3.25)$ & $30(19.48)$ \\
Measles vaccine & $114(74.03)$ & $16(10.39)$ & $24(15.58)$ \\
Rabies vaccine & $84(54.90)$ & $4(2.61)$ & $65(42.48)$ \\
Yellow fever vaccine & $80(51.95)$ & $29(18.83)$ & $45(29.22)$ \\
Hepatitis B vaccine & $66(42.86)$ & $16(10.39)$ & $72(46.75)$ \\
Oral polio vaccine & $66(42.86)$ & $59(38.31)$ & $29(18.83)$ \\
Hepatitis A vaccine & $65(42.21)$ & $16(10.39)$ & $73(47.40)$ \\
Rotavirus vaccine & $63(40.91)$ & $35(22.73)$ & $56(36.36)$ \\
$\begin{array}{l}\text { DPT vaccine } \\
\text { Tuberculosis [BCG] } \\
\text { vaccine }\end{array}$ & $58(37.66)$ & $11(7.14)$ & $85(55.19)$ \\
$\begin{array}{l}\text { N. meningitis } \\
\text { Pneumococcal }\end{array}$ & $52(33.99)$ & $31(20.26)$ & $70(45.75)$ \\
vaccine & $38(24.68)$ & $25(16.24)$ & $91(59.09)$ \\
\hline
\end{tabular}


When asked to volunteer some benefits of vaccination to one's child, the respondents most commonly mentioned "prevention of potential spread of disease" (48.1\%), "prevention of measles" (41.0\%), "prevention of polio" (39.1\%), and "prevention of tetanus" (18.6\%). The most common vaccine example given was the tetanus toxoid vaccine $(77.3 \%)$, followed by the measles vaccine $(74.0 \%)$, and the rabies vaccine (54.9\%). Other vaccines identified included the yellow fever vaccine $(52.0 \%)$, hepatitis B vaccine $(42.9 \%)$, and the oral polio vaccine $(42.9 \%)$.

\section{Attitudes and practices towards childhood vaccination}

When queried "Does every child have the right to vaccination?" nearly all the study subjects (94.8\%) responded affirmatively. The majority of the participants $(66.2 \%)$ responded "No" to the question "Is there anything that can possibly replace vaccines for children?", but onethird either disagreed (20.8\%) or 'did not know' (13.0\%). The most important factors cited by the participants to influence the decision to go to an immunization center included a recommendation by a local nurse (13.2\%) or other health official (10.4\%), support from a spouse (11.8\%), and community announcements (10.3\%). Almost all of the participants (98\%) could not give reasons that might prevent them from going to the immunization clinic or prevent them from vaccinating their child (Table 3).

Table 3 Attitudes and practices towards vaccination of parents and caregivers.

\begin{tabular}{|c|c|c|c|}
\hline \multirow[b]{2}{*}{ Attitudes and practices } & \multicolumn{3}{|c|}{ Response $=n(\%)$} \\
\hline & Yes & No & $\begin{array}{l}\text { Don't } \\
\text { know }\end{array}$ \\
\hline & $146(94.81)$ & $6(3.90)$ & $2(1.30)$ \\
\hline & $32(20.78)$ & $102(66.23)$ & $20(12.99)$ \\
\hline $\begin{array}{l}\text { Possible replacement of } \\
\text { vaccines for children }\end{array}$ & $138(94.52)$ & $8(5.48)$ & $\begin{array}{l}\text { Not } \\
\text { applicable }\end{array}$ \\
\hline $\begin{array}{l}\text { Factors that encourage } \\
\text { the decision to go to } \\
\text { immunization clinic }\end{array}$ & Mentioned & $\begin{array}{l}\text { Not } \\
\text { mentioned }\end{array}$ & \\
\hline Local nurse & $19(13.19)$ & $125(86.81)$ & \\
\hline Support from husband & $17(11.81)$ & $127(88.19)$ & \\
\hline $\begin{array}{l}\text { Message from } \\
\text { community }\end{array}$ & $15(10.27)$ & 131(89.73) & \\
\hline Other local official & $15(10.42)$ & $129(89.58)$ & \\
\hline Peer pressure & $11(7.69)$ & 132(92.31) & \\
\hline Opinion leaders & $2(1.40)$ & $141(98.60)$ & \\
\hline \multicolumn{4}{|c|}{$\begin{array}{l}\text { Factors that negatively influence people } \\
\text { from going to immunization clinic }\end{array}$} \\
\hline $\begin{array}{l}\text { Unwelcoming health } \\
\text { worker }\end{array}$ & $3(2.00)$ & $147(98.00)$ & \\
\hline $\begin{array}{l}\text { I feel my child does not } \\
\text { need the vaccine }\end{array}$ & $3(2.00)$ & $147(98.00)$ & \\
\hline $\begin{array}{l}\text { It is too far from where } \\
\text { I live }\end{array}$ & $3(2.03)$ & 145(97.97) & \\
\hline Cost involved & $1(0.67)$ & $149(99.33)$ & \\
\hline Side effect of vaccines & $1(0.67)$ & $149(99.33)$ & \\
\hline
\end{tabular}

The vaccination status of children categorized into 'scheduled', 'unscheduled' or 'not recorded' are provided in Table 4. Scheduled immunization coverage was highest at birth. This included the BCG vaccine (43.0\%) and the first dose oral polio vaccine (49.4\%). The scheduled immunization coverage for the subsequent second, third, and fourth oral polio vaccine doses were 19.2\%, $13.5 \%$ and $10.3 \%$, respectively. The pentavalent vaccine Diphtheria-Tetanus-Pertussis/ Haemophilus influenzae B/ Hepatitis B (DTP/Hib/Hep B) scheduled rates were highest for the first dose at 6 weeks (16.7\%), and lower for the subsequent doses: 2 nd dose at 10 weeks $(11.5 \%)$ and 3rd dose at 14 weeks (9.0\%), respectively. The scheduled vaccine coverage for the more recently introduced vaccines into the Ghana EPI (Pneumococcal Conjugate Vaccine: PCV 1-3; Rotavirus Vaccine: RV 1-3; and the 2nd dose Measles Vaccine: MV 2) were 3.85\%, $3.21 \%$ and $3.85 \%$ (for PCV 1 to 3 respectively), $6.41 \%$, $5.77 \%$ and $3.85 \%$ (for RV 1 to 3 respectively) and $0 \%$ (for the second dose measles vaccine) (Table 4). Respondents having a primary level education had the highest rates of scheduled or unscheduled vaccinations across all infant vaccines. The ratio of primary level education scheduled vaccination rate to secondary level education scheduled vaccination rate for the newly introduced vaccines ranged from 1:1 for PCV 1 and PCV 2 through 2:1 for RV1 to 3:1 for PCV3, and RV2 and 3 (Table 5). With a primary educational level, unscheduled rates of vaccination were highest for RV3 (90\%), PCV 1 (86\%) and RV1 (84\%) (Table 5). Table 5 gives the scheduled and unscheduled rates for some selected vaccines. These vaccines were selected firstly because they were the ones showing a 1:5-6 ratio for scheduled and unscheduled rates of vaccination between primary and secondary levels of education (except scheduled rates for RV1 and PCV1). Secondly, they represent vaccines from day 0 as well as later stage vaccines when there is the expected trend of waning adherence to scheduled visits for later vaccines. Thirdly, it includes the pentavalent 3 vaccine (which contains the DTP3, often used as an indicator for vaccine coverage in children) [27], as well as the newer vaccines (RV and PCV) in the Ghana EPI. The complete lists of scheduled and unscheduled rates for all individual vaccines are available upon request. A logistic regression analysis of vaccines and demographic characteristics was done (Table 6). It showed that the odds of an unschooled (OR 1.76, p value $=0.465$ ) or unemployed parent or caregiver (OR 2.48, $\mathrm{p}$ value $=0.408$ ) with more than 4 children (OR 2.49, p value $=0.273$ ) having a 1 month to 5 -year old child vaccinated with the pentavalent 3 is approximately two times compared to a schooled or employed parent/ caregiver with $\leq 4$ children. However, not being married was associated with a lower odds (OR 0.36 , $p$ value $=0.121$ ) of having a child aged 1 month to 5 -years being vaccinated with pentavalent 3 . 
Table 4 Adherence rates to vaccination schedules among parents and caregivers.

\begin{tabular}{|c|c|c|c|}
\hline \multirow{2}{*}{ Vaccines, $N=156$} & \multicolumn{3}{|c|}{ Vaccination status } \\
\hline & Scheduled, $n(\%)$ & Unscheduled, $n(\%)$ & Not recorded, $n(\%)$ \\
\hline BCG (at birth) & $67(42.95)$ & $52(33.33)$ & $37(23.72)$ \\
\hline Oral polio 1st dose (at birth) & $77(49.36)$ & $18(11.54)$ & 61(39.10) \\
\hline Oral polio 2nd dose (6wks) & $30(19.23)$ & $79(50.64)$ & $47(30.13)$ \\
\hline Oral polio 3rd dose (10wks) & $21(13.46)$ & $86(55.13)$ & $49(31.41)$ \\
\hline Oral polio 4th dose (14wks) & $16(10.26)$ & $85(54.49)$ & $55(35.26)$ \\
\hline \multicolumn{4}{|l|}{ Pentavalent vaccines: } \\
\hline DTPHibHep 1st dose (6wks) & $26(16.67)$ & $80(51.28)$ & $50(32.05)$ \\
\hline DTPHibHep 2nd dose (10wks) & $18(11.54)$ & $87(55.77)$ & $51(32.69)$ \\
\hline DTPHibHep 3rd dose (14wks) & $14(8.97)$ & $82(52.56)$ & $60(38.46)$ \\
\hline Pneumococcal 1st dose (6wks) & $6(3.85)$ & $21(13.46)$ & $129(82.69)$ \\
\hline Pneumococcal 2nd dose (10wks) & $5(3.21)$ & $21(13.46)$ & $130(83.33)$ \\
\hline Pneumococcal 3rd dose (14wks) & $6(3.85)$ & $16(10.26)$ & $134(85.90)$ \\
\hline Rotavirus 1st dose (6wks) & $10(6.41)$ & $25(16.03)$ & $121(77.56)$ \\
\hline Rotavirus 2nd dose (10wks) & $9(5.77)$ & $25(16.03)$ & $122(78.21)$ \\
\hline Rotavirus 3rd dose (14wks) & $6(3.85)$ & $10(6.41)$ & $140(89.74)$ \\
\hline Measles 1st dose(9mths) & $42(26.92)$ & $35(22.44)$ & $79(50.64)$ \\
\hline Measles 2nd dose (18mths) & $0(0)$ & $0(0)$ & $156(100)$ \\
\hline Yellow fever 1st dose (9mths) & $43(27.56)$ & $35(22.44)$ & $78(50.00)$ \\
\hline
\end{tabular}

Table 5 Scheduled and unscheduled rates of selected vaccines according to parental educational level.

\begin{tabular}{|c|c|c|c|c|c|c|c|c|c|c|c|c|}
\hline \multirow[b]{3}{*}{ Education level } & \multicolumn{12}{|c|}{ Scheduled } \\
\hline & \multicolumn{2}{|c|}{$B C G$} & \multicolumn{2}{|c|}{ OPVO } & \multicolumn{2}{|c|}{ Measles 1} & \multicolumn{2}{|c|}{ Yellow fever } & \multicolumn{2}{|c|}{ PCV1 } & \multicolumn{2}{|c|}{$R V 1$} \\
\hline & number & $\%$ & Number & $\%$ & Number & $\%$ & Number & $\%$ & Number & $\%$ & Number & $\%$ \\
\hline None & 13 & 19.40 & 22 & 3 & 14 & 32.56 & 14 & 32.56 & 1 & 16.67 & 1 & 10.00 \\
\hline Primary & 41 & 61.19 & 45 & 8 & 22 & 53.49 & 23 & 53.49 & 2 & 33.33 & 5 & 50.00 \\
\hline Secondary & 7 & 10.45 & 7 & 2 & 5 & 11.63 & 5 & 11.63 & 2 & 33.33 & 3 & 30.00 \\
\hline Other & 6 & 8.96 & 3 & 1 & 1 & 2.33 & 1 & 2.33 & 1 & 16.67 & 1 & 10.00 \\
\hline \multirow[t]{3}{*}{ Total } & 67 & & 77 & 14 & 42 & & 43 & & 6 & & 10 & \\
\hline & \multicolumn{12}{|c|}{ Unscheduled } \\
\hline & \multicolumn{2}{|c|}{$B C G$} & \multicolumn{2}{|c|}{ OPVO } & \multicolumn{2}{|c|}{ Pentavalent 3} & \multicolumn{2}{|c|}{ Measles 1} & \multicolumn{2}{|c|}{ PCV1 } & \multicolumn{2}{|c|}{$R V 1$} \\
\hline Education level & number & $\%$ & Number & $\%$ & Number & $\%$ & Number & $\%$ & Number & $\%$ & Number & $\%$ \\
\hline None & 16 & 30.77 & 1 & 5.56 & 21 & 25.61 & 9 & 25.71 & 2 & 9.52 & 3 & 12.00 \\
\hline Primary & 28 & 53.85 & 12 & 66.67 & 49 & 59.76 & 24 & 68.57 & 18 & 85.71 & 21 & 84.00 \\
\hline Secondary & 6 & 11.54 & 2 & 11.11 & 8 & 9.76 & 1 & 2.86 & 1 & 4.76 & 1 & 4.00 \\
\hline Other & 2 & 3.85 & 3 & 16.67 & 4 & 4.88 & 1 & 2.86 & 0 & 0.00 & 0 & 0.00 \\
\hline Total & 52 & & 18 & & 82 & & 35 & & 21 & & 25 & \\
\hline
\end{tabular}

Note: 'Unrecorded' vaccination status has been excluded 
Table 6 Logistic regression of vaccines and demographic characteristics.

\begin{tabular}{|c|c|c|c|c|c|c|c|c|c|c|}
\hline \multirow{2}{*}{$\begin{array}{l}\text { Vaccines } \\
\text { Factors }\end{array}$} & \multicolumn{2}{|l|}{ BCG } & \multicolumn{2}{|l|}{ OPV 0} & \multicolumn{2}{|c|}{ Pentavalent 3} & \multicolumn{2}{|l|}{ Measles } & \multicolumn{2}{|c|}{ Yellow Fever } \\
\hline & OR (95\%CI) & $\begin{array}{c}\text { p- } \\
\text { value }\end{array}$ & OR $(95 \% \mathrm{CI})$ & $\begin{array}{c}\text { p- } \\
\text { value }\end{array}$ & OR (95\%CI) & $\begin{array}{c}\mathrm{p}- \\
\text { value }\end{array}$ & OR (95\%CI) & $\begin{array}{c}\mathrm{p}- \\
\text { value }\end{array}$ & OR (95\%CI) & $\begin{array}{c}\mathrm{p}- \\
\text { value }\end{array}$ \\
\hline \multicolumn{11}{|l|}{ Education } \\
\hline Schooled & (reference) & & (reference) & & (reference) & & (reference) & & (reference) & \\
\hline Unschooled & $1.95(0.76-5.02)$ & 0.17 & $0.13(0.02-1.17)$ & 0.07 & $1.76(0.39-8.00)$ & 0.47 & $0.56(0.19-1.69)$ & 0.3 & $0.60(0.20-1.78)$ & 0.36 \\
\hline \multicolumn{11}{|l|}{ Marital status } \\
\hline Married & (reference) & & (reference) & & (reference) & & (reference) & & (reference) & \\
\hline Not married & $0.75(0.31-1.82)$ & 0.52 & $0.88(0.23-3.29)$ & 0.84 & $0.36(0.10-1.31)$ & 0.12 & $1.43(0.51-3.98)$ & 0.49 & $1.25(0.46-3.44)$ & 0.66 \\
\hline \multicolumn{11}{|c|}{ Number of children } \\
\hline$\leq 4$ & (reference) & & (reference) & & (reference) & & (reference) & & (reference) & \\
\hline \multicolumn{11}{|l|}{ Profession } \\
\hline Employed & (reference) & & (reference) & & (reference) & & (reference) & & (reference) & \\
\hline Unemployed & $1.32(0.49-3.58)$ & 0.58 & $1.69(0.44-6.54)$ & 0.45 & $\begin{array}{c}2.48(0.29- \\
21.19)\end{array}$ & 0.41 & $1.36(0.35-5.27)$ & 0.66 & $1.38(0.36-5.34)$ & 0.64 \\
\hline
\end{tabular}

Note: The other vaccines were dropped because of fewer numbers; P-value $>0.5$ (in bold) considered significant.

Abbreviations: $\mathrm{OR}=$ Odds Ratio; $\mathrm{CI}=$ Confidence Interval.

\section{Discussion}

This study explored the knowledge, attitudes, and practices of parents and caregivers regarding child immunization in a rural subdistrict in Ghana. Our results indicate that there is almost universal awareness of the conduct of immunization among the participants in the Barekuma Community. However, there are also substantial knowledge gaps regarding the benefits of the practice and poor adherence to recommended vaccine schedules, especially beyond the neonatal period. Timeliness of vaccine uptake has been associated with hospital delivery [28], a time when the initial vaccines are given, and, in general, vaccination schedule adherence tends to decrease subsequently with later vaccines [21-23] as was found to be the case in our study. Common sources of vaccination awareness were the hospitals / clinics or the media (radio and television stations) or community announcements with a Public Address System. This underscores the importance of these avenues in promoting public awareness of health interventions. However, the gap in the general level of awareness about the benefits of vaccination and the risks of no vaccination among the sampled population may negatively impact the health seeking behaviour of participants (in agreement with the HBM) if measures are not put in place to improve upon vaccination education.

A study on the knowledge, attitudes and practices of immunization in an urban educated population [13] identified not only considerable variation in vaccine awareness from one vaccine to another, but also generally lower scores related to vaccine schedules. Although our study did not specifically ask about schedule related knowledge, a substantial gap in knowledge seems plausible based on the low rates of scheduled vaccination coverage reported for various vaccines. However, low rates of scheduled vaccination coverage may also be due to other factors that need to be explored in further studies.

Illiteracy has been blamed as a reason for delayed vaccination $[29,30]$, but the educational level of the mother (or parent) can also influence the health status of the child [14, 31, 32]. For instance, Browne et al. [14] found that full immunization coverage of the children of mothers who had been educated beyond primary level was higher than that of the other children (75.9\% v. $65.2 \%)$ in Kumasi, in 1999. Our results, however, showed parents or caregivers with a primary educational level overall, had the highest rates of either scheduled or unscheduled vaccinations. And, with the exception of the vaccines newly introduced into the EPI (PCV and RV), the rate of scheduled vaccinations were about 5 to 6 times higher for parents or caregivers with primary level education than they were for those with secondary level education (although our study was not adequately powered to detect such a difference) (Table 5). Moreover, the odds of having a child who has had a scheduled pentavalent 3 or BCG vaccine was nearly twice for unschooled compared to schooled parents or caregivers, although it was much less for OPV0 (OR 0.13, p value $=0.07$ ), measles (OR 0.56, $p$ value $=0.304)$ and yellow fever $(\mathrm{OR} 0.6$, p value $=0.36)$ (Table 6). Nonetheless, it is important to take note that in our study, less than $20 \%$ of caretakers had reported education beyond primary school.

The finding of a higher rate of scheduled vaccination in parents with primary education was unexpected and inconsistent with findings from other studies where 
higher vaccination rates were associated with higher maternal education [14, 31]; nor were the findings of higher odds of scheduled vaccinated children for unschooled, unemployed parents with $>4$ children. The reasons for these paradoxical findings from our study are not immediately apparent, but may have been due to the following. Firstly, itis plausible that parents with primary or no education are more available for vaccination schedules (say from less restrictive occupational engagements) compared to parents with higher education. Secondly, it is possible our study may have missed the effect of other hidden variables accounting for these associations. On this latter account, it has been found, for instance, that paternal education of secondary or higher level is significantly and independently correlated with measles immunization uptake after controlling for all potential confounders, independent of maternal education status [32]. Since our study respondents were almost all mothers, we could have missed the important contribution of the paternal education. It could be that paternal education is a more important factor for (scheduled) vaccine uptake in the Barekese subdistrict. In such a case, the influence of maternal education will be insignificant. Although we cannot infer from our current data, these represent key topics to be explored in depth in future studies.

Elsewhere, studies have indicated that understanding the parental perceptions and knowledge about immunizations would help health policy makers to develop better health education programmes [15-19]. Reasons found for non-completion of immunization included not only illiteracy or lower education but also a lack of understanding of the benefits of immunization. For instance in an urban settlement of Papua New Guinea, Bukenya and Freeman [33] found that among 194 mothers of children aged 1 to 2 years, $87 \%$ did not know why children should be immunized. In that study, only $13 \%$ believed immunizations could prevent disease. Other reasons identified by Bukenya and Freeman [33] for non-completion of the immunizations included rude behaviour on the part of the health staff $(76.8 \%)$ and aggressive reaction from the health staff (15.5\%). Only $7.7 \%$ of the mothers reported kind behaviour from health workers in their study. Mothers who perceived health staff attitudes as negative were more likely to fail to complete the schedule.

In our study, we found that in spite of the apparent deficiencies in knowledge, the participants' general attitudes and practices towards childhood vaccination were positive. The majority of the participants agreed that every child has the right to vaccination and that there is no substitute to this. The participants were unlikely to identify reasons that might prevent them from attending immunization clinics. In other words, aside the few reasons cited by the minority of subjects (Table 3) such as an unwelcoming health worker, fear of side effects, cost of vaccines, and a long distance from immunization clinics, participants cited no perceived barriers to vaccination of their children. This implies proper education and motivation of these parents could very likely improve attendance and compliance with scheduled vaccine visits. This is in line with the HBM [20, 34]. As the model suggests, individuals will take appropriate preventive action (ie. compliance with scheduled vaccination clinic visits to have their children vaccinated) in response to a perceived level of threat (ie. awareness of the risk of vaccine preventable diseases in unvaccinated children, along with their complications) if the benefits of the new behaviour (ie. healthy, immune children) outweigh the barriers (eg. unwelcoming health professional, long distance to vaccination clinic, costs, fear of vaccine side effects, etc.). Other studies have found that although the mothers/caregivers raised concerns about the costs of the routine immunizations, these charges apparently did not prevent them from taking their children to be immunized [14].

Lastly, the key persons that are likely to influence the decision to attend the immunization clinics include the nurse or other health worker, and a supportive spouse. These individuals, as well as the use of community address systems, represent invaluable assets in ensuring that every child will participate in the routine EPI schedule and/ or National Immunization Days (NIDs) according to the recommendations. The NIDs are specific days designated for immunization of children aged 0 to 9 months in Ghana as a "catch-up" strategy to reach children who may have missed their scheduled vaccination on the EPI [35].

However, it is also important to ensure that other concerns raised, such as an unwelcoming health worker or distant immunization center, or fear of vaccine side effects, which, though were not major findings in this study but have been identified in other studies [36] are addressed through education of the community and health providers as well as the utilization of mobile vaccinators and provision of more accessible vaccination centers.

\section{Study limitations}

The random cross-sectional study sample was limited by unavailability of some parents at the time of the interviews which may have introduced a selection bias. Caregivers with higher education levels may be more likely to be engaged in employment at a remote location at the time of interviews, skewing the population studied. In addition, there may have been recall bias in some responses, as negative experiences may have been more memorable. A response bias is also possible, as respondents may be more likely to provide answers which they perceive as desired by the interviewer.

\section{Conclusions}

The findings from this study suggest that there is a high level of awareness of vaccination and the National Immunization Days among parents and caregivers of children aged 1 month to 5 years in the Barekese subdistrict of Ghana. However, there is insufficient awareness of the benefits of vaccination and the diseases preventable by the EPI vaccines. Nonetheless, the participants' attitudes and practices towards childhood vaccination remain positive, although scheduled vaccination rates are generally very low. It is essential to increase public 
awareness of the overwhelming benefits of childhood vaccination in reducing morbidity and mortality, while providing responses to the fears of the side effects of vaccines through education in our attempts at improving U5M rates through wider vaccine coverage to halt infectious disease circulation. There should be proactive education of caregivers and parents at the immunization centers to increase vaccines, immunization, and vaccine schedule related knowledge so as to improve adherence to scheduled visits. There should be a system of notifying parents and caregivers to prompt them on upcoming scheduled vaccine visits. This is, however, logistically limited but may be explored in further studies. Such prompting mechanisms could include the use of mobile phones and community volunteers.

\section{Acknowledgements}

The authors are grateful to the staff of the Research and Development Unit, Komfo Anokye Teaching Hospital, Kumasi, as well as those who were involved in data collection from University of Utah and the Kwame Nkrumah University of Science and Technology.

\section{Conflict of interest}

The authors declare no conflict of interest.

\section{References}

[1] Ehreth J (2003) Value of vaccines. Vaccine 21:4111.

[2] WHO (2014) Global Vaccine Action Plan 2011-2020. Page 29. Assessed August 9, 2014: http://www.unicef.org/immunization/ files/GlobalVaccineActionPlan.pdf

[3] Wang H, Dwyer-Lindgren L, Lofgren KT, Rajaratnam JK, Marcus JR, et al. (2012) Age-specific and sex-specific mortality in 187 countries, 1970-2010: a systematic analysis for the Global Burden of Disease Study 2010. Lancet 380: 2071-2094.

[4] Black RE, Cousens S, Johnson HL, Lawn JE, Rudan I, et al. (2010) Global, regional, and national causes of child mortality in 2008: a systematic analysis. Lancet 375: 1969-1987.

[5] Centers for Disease Control and Prevention (2012) Vaccines and Immunizations. Assessed August 4, 2014: http://www.cdc.gov/ vaccines/vac-gen/imz-basics.htm

[6] Ozawaa S, Mirelmana A, Stacka ML, Walkerb DG, and Levinea OS (2012) Cost-effectiveness and economic benefits of vaccines in low- and middle-income countries: A systematic review. Vaccine 31:96-108.

[7] Idoko OT, Kochhar S, Agbenyega TE, Ogutu B, Ota MOC (2013) Impact, Challenges, and Future Projections of Vaccine Trials in Africa. Am J Trop Med Hyg 88:414-419.

[8] WHO (2010) Infectious disease report. Assessed May 25, 2014. http://www.who.int/infectious-disease-report/pages/textonly. html

[9] UNICEF (2007) The state of the world's children 2008. Assessed May 25, 2014: http://www.unicef.org/sowc08/docs/sowc08.pdf

[10] United Nations (2013) The Millenium Development Goals Report 2013. Assessed May 25, 2014: http://mdgs.un.org/unsd/mdg/ Resources/Static/Products/Progress2013/Goal4_Addendum.pdf

[11] WHO (2010) WHO vaccine-preventable diseases: monitoring system-2010 global summary. Assessed August 5, 2014: http:// whqlibdoc.who.int/hq/2010/WHO_IVB_2010_eng.pdf

[12] Barman D, Dutta A (2013). Access and barriers to immunization in West Bengal, India: quality matters. J Health Popul Nutr 31:510522.

[13] Shah B, Sharma M, Vani SN (1991) Knowledge, attitude and practice of immunization in an urban educated population. Indian J Pediatr 58:691-695.
[14] Browne EN, Bonney AA, Agyapong FA, Essegbey IT (2002) Factors influencing participation in national immunization days in Kumasi, Ghana. Ann Trop Med Parasitol 96:93-104.

[15] Munthali AC (2007) Determinants of vaccination coverage in Malawi: evidence from the demographic and health surveys. Malawi Med J 19:79-82.

[16] Ibnouf AH, Van den Bourne HW, Maarse JA (2007) Factors influencing immunization coverage among children under five years of age in Khartoum state, Sudan. South African Family Practice 49:14.

[17] Weeks M, Stelngalss R (1996) Beyond Immunization to Disease Control. Child Survival BASICS Quaterly Technical Newsletter 3:8-9.

[18] Murthy GV, Kumar S (1989) Knowledge of mothers regarding immunization in a high coverage area--need for strengthening health education. Indian Pediatr 26:1219-1222.

[19] Singh MC, Badole CM, Singh MP (1994) Immunization coverage and the knowledge and practice of mothers regarding immunization in rural area. Indian J Public Health 38:103-107.

[20] ETR (2007-2009) Resource center for adolescent pregnancy prevention. Assessed July 21, 2014: http://www.etr.org/recapp/ theories/hbm/Resources.htm

[21] Babirye JN1, Engebretsen IM, Makumbi F, Fadnes LT, Wamani H, et al. (2012) Timeliness of childhood vaccinations in Kampala Uganda: a community-based cross-sectional study. PLoS One 7:e35432.

[22] Fadnes LT1, Jackson D, Engebretsen IM, Zembe W, Sanders D, et al. (2011) Vaccination coverage and timeliness in three South African areas: a prospective study. BMC Public Health 11:404.

[23] Laryea DO, Abbeyquaye Parbie E, Frimpong E (2014) Timeliness of childhood vaccine uptake among children attending a tertiary health service facility-based immunisation clinic in Ghana. BMC Public Health 14:90.

[24] BCCDP (2009) Barekuma Collaborative Community Development Project Report for 2009. Assessed May 25, 2014: http://www. globalhealth.utah.edu/documents/BCCDP_2009.pdf

[25] Ghana Statistical Service (GSS), Ghana Health Service (GHS), and ICF Macro (2009) Ghana Demographic and Health Survey 2008. Assessed August 5, 2014: http://pdf.usaid.gov/pdf_docs/ PNADQ630.pdf

[26] Naing L, Winn T, Rusli BN (2006) Practical issues in calculating the sample size for prevalence studies. Archives of Orofacial Sciences 1:9-14.

[27] Informal consultation of developing a monitoring and accountability framework for the Global Vaccine Action Plan (2012). The monitoring and evaluation/ accountability framework for the Global Vaccine Action Plan- The monitoring Indicators. Assessed August 5, 2014: http://www.who.int/immunization/ sage/meetings/2012/november/2_MA_Framework_monitoring_ indicators_final.pdf

[28] Olusanya BO (2010) Pattern and determinants of BCG immunisation delays in a sub-Saharan African community. Health Res Policy Syst 8:1.

[29] Singh P, Yadav RJ (2001) Immunization status of Children in BIMARU States. Indian J Pediatr 68:495-499.

[30] Singh H, Kaur L, Kataria SP (1990) Reasons for delayed vaccination. Indian Pediatr 27:387-390.

[31] No authors listed (2013) Child vaccinations in Ghana: which children benefit from the National Vaccination Days campaigns? Assessed May 25, 2014: http://paa2013.princeton.edu/ papers $/ 132810$

[32] Rammohan A, Awofeso N, Fernandez RC (2012) Paternal education status significantly influences infants' measles vaccination uptake, independent of maternal education status. BMC Public Health $12: 336$.

[33] Bukenya GB, Freeman PA (1991) Possible reasons for noncompletion of immunization in an urban settlement of Papua New Guinea. P N G Med J 34:22-25.

[34] Rosenstock I (1974) Historical origins of the health belief model. Health Educ Monogr 2(4):328-35.

[35] Ghana Health Service (2014) Expanded Programme on Immunization Assessed May 25, 2014: http://www. ghanahealthservice.org/epi.php

[36] Khanom K, Salahuddin AK (1983) A study on impact of an educational programme on immunization behaviour of parents. Bangladesh Med Res Counc Bull 9:18-24. 